\title{
Exergy analysis of the absorption refrigeration cycle using economizers
}

\section{Análisis exergético del ciclo de refrigeración por absorción utilizando economizadores}

VALENCIA-ALEJANDRO, Eric A. ${ }^{1} \dagger$, HERRERA-ROMERO, José V. ${ }^{1 *}$, COLORADO-GARRIDO, Darío $^{2}$ and SILVA-AGUILAR, Oscar $\mathrm{F}^{1}$

${ }^{1}$ Universidad Veracruzana, Facultad de Ingeniería, Avenida Universidad km 7.5, Colonia Santa Isabel, C.P. 96535, Coatzacoalcos, Veracruz 96535, México.

${ }^{2}$ Universidad Veracruzana,Centro de Investigación en Recursos Energéticos y Sustentables, Avenida Universidad km 7.5, Col. Santa Isabel, Coatzacoalcos C.P. 96535, Veracruz, México.

ID $1^{\text {st }}$ Author: Eric André, Valencia-Alejandro

ID $1^{\text {st }}$ Coauthor: José V., Herrera-Romero / ORC ID: 0000-0001-9462-0160, CVU CONACYT ID: 163163

ID $2^{\text {nd }}$ Coauthor: Darío, Colorado-Garrido / ORC ID: 0000-0003-4157-1005, CVU CONACYT ID: 171579

ID $3^{\text {rd }}$ Coauthor: Oscar, Silva-Aguilar / ORC ID: 0000-0002-5109-3193, CVU CONACYT ID: 338659

DOI: $10.35429 / J T D .2019 .14 .4 .7 .14$

Received June 26, 2020; Accepted November 28, 2020

\begin{abstract}
This paper presents the study of a simple effect absorption refrigeration system (SRA) using the ammonia-water working couple, with the incorporation of three economizers and their analysis of the first and second law of thermodynamics, emphasizing the effect of the operating temperatures and the efficiency of the exchangers on the refrigerant circulation ratio (RC), the coefficient of performance (COP) of the system and the destruction of exergy. In order to determine the thermodynamic properties at each point of the system and evaluate the performance of the SRA, was programmed a tool in MATLAB with the governing equations. The results show that: the exergy efficiency increases when the temperature in the evaporator decreases; and RC decreases with increasing temperature in the generator. As conclusion, an increase in the effectiveness of heat exchangers cannot only decrease the refrigerant circulation rate, but also increase the inlet temperature of the solution to the generator, so that the temperature difference between the solution and the heat source decreases, causing a decrease in the rate of exergy destruction in the generator and the increase in COP.
\end{abstract}

Second law analysis, Economizers, $\mathrm{NH}_{3}-\mathrm{H}_{2} \mathrm{O}$

\begin{abstract}
Resumen
Este articulo presenta el estudio de un sistema de refrigeración por absorción (SRA) de simple efecto utilizando el par de trabajo amoniaco-agua, con la incorporación de tres economizadores y su análisis de primera y segunda ley de la termodinámica, enfatizando el efecto de las temperaturas de operación y la eficiencia de los intercambiadores en la relación de circulación (RC) de refrigerante, el coeficiente de operación energético (COP) del sistema y la destrucción de exergía. Con el propósito de determinar las propiedades termodinámicas en cada punto del sistema y evaluar el rendimiento del SRA, se programó una herramienta en MATLAB con las ecuaciones gobernantes. Los resultados muestran que: la eficiencia exergética aumenta cuando disminuye la temperatura en el evaporador; y la RC decrece con el aumento de temperatura en el generador. Se concluyó que un aumento de la efectividad de los intercambiadores de calor no solo puede disminuir la tasa de circulación de refrigerante, sino que también aumentar la temperatura de entrada de la solución al generador, por lo que la diferencia de temperatura entre la solución y la fuente de calor disminuye, provocando una disminución de la tasa de destrucción de exergía en el generador y un aumento en el COP.
\end{abstract}

Análisis de segunda ley, Economizadores, $\mathrm{NH}_{3}-\mathrm{H}_{2} \mathrm{O}$

Citation: VALENCIA-ALEJANDRO, Eric A., HERRERA-ROMERO, José V., COLORADO-GARRIDO, Darío and SILVA-AGUILAR, Oscar F. Exergy analysis of the absorption refrigeration cycle using economizers. Journal of Technological Development. 2020. 4-14: 7-14

\footnotetext{
* Correspondence to Author (email: vidherrera@uv.mx)

$\dagger$ Researcher contributing first author
} 


\section{Introduction}

An absorption refrigeration system (SRA) is a means of cold production that is characterized by operating with a low temperature heat source (Kaynakli and Kilic), so that they can be powered by low-cost alternative energy such as biomass, solar energy, geothermal energy or waste heat. The application of the first law of thermodynamics is very convenient to make a study of the conservation of energy within the system. However, a first law analysis cannot show how or where irreversibilities occur (Aphornratana and Eames). A second law analysis determines the magnitude of irreversible processes in a system, and thus points the direction in which engineers should focus their efforts to improve cycle performance.

The main drawback of an SRA is that energy efficiency is usually very low. The application of technology for the reuse of thermal energy within the system turns out to be a very effective alternative to raise the cycle's operating coefficient.

In this research, the set of equations that model the thermodynamic properties of the system is developed, relying on the MATLAB programming tool for its resolution. In addition to graphically illustrating the results obtained and discussing the importance of using economizers in the cycle to maximize the use of the available energy resource.

\section{System description}

Figure 1 shows a schematic diagram of a singleacting SRA. It illustrates the essential components of any absorption refrigeration cycle: absorber, pump, condenser, evaporator, generator, refrigerant expansion valve (VER), and solution expansion valve (VES). SRAs are characterized by the fact that the refrigerant is absorbed by an element on the low pressure side of the system, and released on the high pressure side (Faires and Simmang), referring to the absorber and generator, which replace the compressor of a conventional mechanical refrigeration system. When it comes to the operation of an SRA, a low ammonia, high water content mixture (dilute solution) flows from the generator to the absorber, decreasing its pressure as it passes through the VES in an isentropic manner.
In the absorber, its affinity to ammonia is used to capture refrigerant from the evaporator. The absorption process between the ammonia-water mixture $(\mathrm{NH} 3-\mathrm{H} 2 \mathrm{O})$ is exothermic, so it is necessary to remove heat to preserve its temperature. To keep the cycle running, the new high-content refrigerant solution (concentrated solution) is pumped to the high-pressure side, where it is heated to the boiling point of the refrigerant, causing ammonia vapor to escape into the condenser, at which is condensed.

Next, the zero quality refrigerant continues its journey through the isentropic VER until it reaches the evaporator with a low temperature. The latent heat necessary for the vaporization of the refrigerant is taken from the space to be cooled, thus creating the desired cooling effect. Finally, the refrigerant vapor flows from the evaporator to the absorber, where it is dissolved in the dilute solution, completing the cycle.

In the studied system, it is proposed to add a solution heat exchanger (ICS) between the concentrated solution that goes to the generator and dilute solution with high temperature that returns from the generator to the absorber. As the temperature of the concentrated solution is increased and the temperature of the dilute solution is reduced, this modification provides a reduction both in the heat supplied in the generator, and in the cooling required by the absorber (Herrera and Colorado).

In the same way, with the intention of reusing the thermal energy that the ammonia vapor has at the generator outlet and that will necessarily have to be dissipated in the condenser, it was proposed to place a solutionrefrigerant heat exchanger (ICSR) with what which would increase the temperature of the $\mathrm{NH} 3-\mathrm{H} 2 \mathrm{O}$ mixture coming from the absorber. Similarly, by installing a refrigerant heat exchanger (ICR) in the refrigerant line that leaves the condenser to the evaporator and that goes from the evaporator to the absorber, the cooling effect is increased, subcooling the liquid entering the evaporator. 


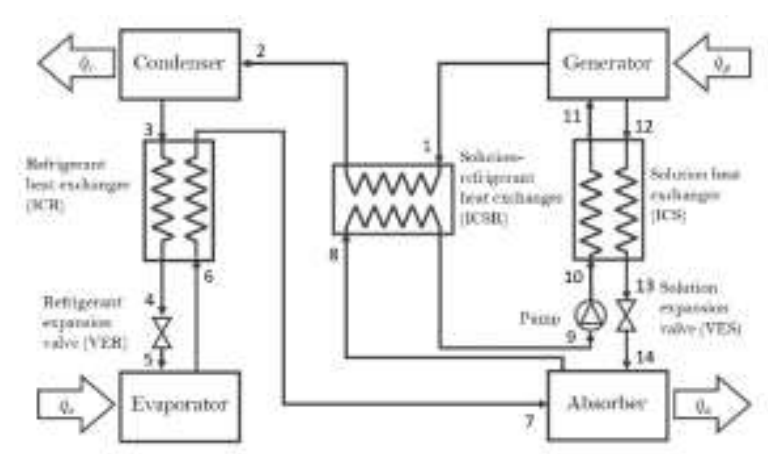

Figure 1 Schematic diagram of the absorption refrigeration cycle with economizers

\section{First law analysis}

For each component shown in Figure 1, the balance of energy, mass and matter can be calculated as follows

Generator

$$
\begin{aligned}
& \dot{Q}_{g}=\dot{m}_{1} h_{1}+\dot{m}_{12} h_{12}-\dot{m}_{11} h_{11} \\
& \dot{m}_{1}=\dot{m}_{11}-\dot{m}_{12} \\
& \dot{m}_{1} x_{1}=\dot{m}_{11} x_{11}-\dot{m}_{12} x_{12}
\end{aligned}
$$

\section{Condenser}

$$
\begin{aligned}
& \dot{Q}_{c}=\dot{m}_{2}\left(h_{2}-h_{3}\right) \\
& \dot{m}_{2}=\dot{m}_{3} \\
& \dot{m}_{1} x_{1}=\dot{m}_{2} x_{2}
\end{aligned}
$$

\section{ICR}

$$
\begin{aligned}
& \dot{m}_{3} h_{3}+\dot{m}_{6} h_{6}=\dot{m}_{4} h_{4}+\dot{m}_{7} h_{7} \\
& \dot{m}_{3}+\dot{m}_{6}=\dot{m}_{4}+\dot{m}_{7} \\
& \dot{m}_{6} x_{6}+\dot{m}_{3} x_{3}=\dot{m}_{4} x_{4}+\dot{m}_{7} x_{7}
\end{aligned}
$$

\section{VER}

$$
\begin{aligned}
& \dot{m}_{4} h_{4}=\dot{m}_{5} h_{4} \\
& \dot{m}_{4}=\dot{m}_{5} \\
& \dot{m}_{4} x_{4}=\dot{m}_{5} x_{5}
\end{aligned}
$$

Evaporator

$$
\begin{aligned}
& \dot{Q}_{e}=\dot{m}_{6}\left(h_{6}-h_{5}\right) \\
& \dot{m}_{5}=\dot{m}_{6}
\end{aligned}
$$

$$
\dot{m}_{5} x_{5}=\dot{m}_{6} x_{6}
$$

Absorber

$$
\begin{aligned}
& \dot{Q}_{a}=\dot{m}_{7} h_{7}-\dot{m}_{8} h_{8}+\dot{m}_{14} h_{14} \\
& \dot{m}_{8}=\dot{m}_{7}+\dot{m}_{14} \\
& \dot{m}_{8} x_{8}=\dot{m}_{14} x_{14}+\dot{m}_{7} x_{7}
\end{aligned}
$$

\section{ICSR}

$$
\begin{aligned}
& \dot{m}_{1} h_{1}+\dot{m}_{8} h_{8}=\dot{m}_{2} h_{2}+\dot{m}_{9} h_{9} \\
& \dot{m}_{1}+\dot{m}_{8}=\dot{m}_{2}+\dot{m}_{9} \\
& \dot{m}_{1} x_{1}+\dot{m}_{8} x_{8}=\dot{m}_{2} x_{2}+\dot{m}_{9} x_{9}
\end{aligned}
$$

Pumb

$$
\begin{aligned}
& \dot{W}_{\text {iso }}=\dot{m}_{9}\left(h_{10}-h_{9}\right) \\
& \dot{m}_{9}=\dot{m}_{10} \\
& \dot{m}_{9} x_{9}=\dot{m}_{10} x_{10}
\end{aligned}
$$

\section{ICS}

$$
\begin{aligned}
& \dot{m}_{10} h_{10}+\dot{m}_{12} h_{12}=\dot{m}_{11} h_{11}+\dot{m}_{13} h_{13} \\
& \dot{m}_{10}+\dot{m}_{12}=\dot{m}_{11}+\dot{m}_{13} \\
& \dot{m}_{10} x_{10}+\dot{m}_{12} x_{12}=\dot{m}_{11} x_{11}+\dot{m}_{13} x_{13}
\end{aligned}
$$

\section{VES}

$$
\begin{aligned}
& \dot{m}_{13} h_{13}=\dot{m}_{14} h_{14} \\
& \dot{m}_{13}=\dot{m}_{14} \\
& \dot{m}_{13} x_{13}=m_{14} x_{14}
\end{aligned}
$$

The circulation ratio $(\mathrm{RC})$ can be defined as the solution mass flow ratio going from the absorber to the generator $\left(\dot{m}_{11}\right)$ and the mass flow rate of the refrigerant fluid $\left(\dot{m}_{1}\right)$.

$$
R C=\frac{\dot{m}_{11}}{\dot{m}_{1}}=\frac{1-x_{12}}{x_{11}-x_{12}}
$$

Complementary equations

$$
\begin{aligned}
& \dot{m}_{6}=\frac{\dot{Q}_{e}}{h_{6}-h_{5}} \\
& \dot{m}_{11}=\left(\frac{1-x_{12}}{x_{11}-x_{12}}\right) \dot{m}_{1}
\end{aligned}
$$

VALENCIA-ALEJANDRO, Eric A., HERRERA-ROMERO, José V., COLORADO-GARRIDO, Darío and SILVA-AGUILAR, Oscar F. Exergy analysis of the absorption refrigeration cycle using economizers. Journal of Technological Development. 2020 


$$
\dot{m}_{12}=\left(\frac{1-x_{11}}{x_{11}-x_{12}}\right) \dot{m}_{1}
$$

For the energy balance in the ICR and ICS, the equations contained in Kilic and Kaynakli were used as a reference, which were adapted to the numbering contained in Figure 1, as shown below

$$
\begin{aligned}
& h_{4}=h_{3}-\eta_{I C R}\left(h_{7-T 3}-h_{6}\right) \\
& h_{7}=h_{6}+\eta_{I C R}\left(h_{7-T 3}-h_{6}\right) \\
& T_{13}=\eta_{I C S} \cdot T_{10}+\left(1-\eta_{I C S}\right) \cdot T_{12} \\
& h_{10}=h_{9}+\left(P_{11}-P_{8}\right) \frac{v_{8}}{\varepsilon_{b o m b a}} \\
& h_{11}=h_{10}+\left(h_{12}-h_{13}\right)\left(\frac{R C-1}{R C}\right)
\end{aligned}
$$

The balance for the exchange of energy between the concentrated solution and the refrigerant in the ICSR was carried out according to what was proposed by Karamangil, Coskun, Kaynakli and Yamankaradeniz, as follows

$$
\begin{aligned}
& h_{2}=h_{1}-\eta_{I C S R}\left(h_{1}-h_{2-T 8}\right) \\
& h_{9}=h_{8}+\left(h_{1}-h_{2-T 8}\right)\left(\frac{R C}{\eta_{I C S R}}\right)
\end{aligned}
$$

In the analysis carried out, the concentration and enthalpy properties in the ammonia and water solution were obtained from the relationships provided by Sun. The equation used to determine the entropy of the NH3-H2O mixture was elaborated by Soleymani Alamdari, who used the least squares method to determine the best adjusted equation that would relate the values of previous research and those obtained from simulations carried out by the same. In this way I construct a two-variable equation to calculate the entropy of NH3-H2O under saturated liquid conditions. is defined by

The mechanical work done by the pump

$$
W_{m e}=\dot{m}_{8}\left(P_{11}-P_{8}\right)\left(\frac{v_{8}}{\varepsilon_{b o m b a}}\right)
$$

The performance of the system is measured through the operating coefficient (COP).

$$
C O P=\frac{\dot{Q}_{e}}{\dot{Q}_{g}+\dot{W}_{m e}}
$$

In general balance, for the first law analysis it must be fulfilled that

$$
\dot{Q}_{g}+\dot{Q}_{e}+\dot{W}_{m e}=\dot{Q}_{c}+\dot{Q}_{a}
$$

\section{Second law analysis}

Exergy is defined as the maximum reversible work that can be obtained from a fluid (Sözen), and it is determined by

$$
\dot{E}_{i}=\dot{m}_{i}\left[\left(h_{i}-h_{0}\right)-T_{0}\left(s_{i}-s_{0}\right)\right]
$$

The terms $\mathrm{h}_{0}$ and $\mathrm{s} 0$ represent the enthalpy and entropy values of the fluid involved at ambient temperature $\mathrm{T}_{0}$.

The variation of exergy within a constant flow system is equal to the exergy transfer minus the exergy destroyed (Panahi and Bozorgan). The exergetic balance for a constant flow system could be expressed as follows

$$
\begin{gathered}
\Delta \dot{E}=\sum_{\text {in }} \dot{E}_{i}-\sum_{\text {out }} \dot{E}_{i}+\sum_{\text {in }} \dot{Q}(1- \\
\left.\frac{T_{0}}{T}\right)-\sum_{\text {out }} \dot{Q}\left(1-\frac{T_{0}}{T}\right)-\dot{W}
\end{gathered}
$$

For each individual component shown in Figure 1, the equation for the rate of variation of exergy is written as follows

$$
\begin{aligned}
& \Delta \dot{E}_{g}=\dot{E}_{11}-\dot{E}_{1}-\dot{E}_{12}+\dot{Q}_{g}\left(1-\frac{T_{0}}{T_{g}}\right) \\
& \Delta \dot{E}_{C}=\dot{E}_{2}-\dot{E}_{3} \\
& \Delta \dot{E}_{I C R}=\dot{E}_{3}+\dot{E}_{6}-\dot{E}_{4}+\dot{E}_{7} \\
& \Delta \dot{E}_{V E R}=\dot{E}_{4}-\dot{E}_{3} \\
& \Delta \dot{E}_{e}=\dot{E}_{5}-\dot{E}_{6}+\dot{Q}_{e}\left(1-\frac{T_{0}}{T_{e}}\right) \\
& \Delta \dot{E}_{a}=\dot{E}_{7}+\dot{E}_{14}-\dot{E}_{8} \\
& \Delta \dot{E}_{I C S R}=\dot{E}_{8}+\dot{E}_{1}-\dot{E}_{9}-\dot{E}_{2}
\end{aligned}
$$




$$
\begin{aligned}
& \Delta \dot{E}_{b o m b a}=\dot{E}_{9}-\dot{E}_{10}-\dot{W}_{m e} \\
& \Delta \dot{E}_{I C S}=\dot{E}_{10}+\dot{E}_{12}-\dot{E}_{11}+\dot{E}_{13} \\
& \Delta \dot{E}_{V E S}=\dot{E}_{13}-\dot{E}_{14}
\end{aligned}
$$

The heat discarded to the cooling medium both in the condenser and absorber is neglected because it is energy with a very low exergetic potential due to its proximity to the reference temperature (Gonzales C.). In other words, the energy potential to carry out work that these residues have is minimal and therefore disposable.

The exergetic efficiency of the system is calculated with

$$
E C O P=\frac{-\dot{Q}_{e}\left(1-\frac{T_{0}}{T}\right)}{\dot{Q}_{g}\left(1-\frac{T_{0}}{T}\right)+\dot{W}_{m e}}
$$

\section{Discussion of results}

To simplify the analysis of the system, the following considerations were made: (1) due to its low boiling point, it was considered that the concentration and quality of the refrigerant at the generator outlet is pure ammonia in the state of saturated steam; (2) the refrigeration load remains constant at $52.8 \mathrm{~kW}$, which represents approximately 15 tons of refrigeration; (3) the pressure losses, as well as the heat losses / gains along the pipes that connect the equipment are negligible; (4) the system is simulated under steady state conditions; (5) the condenser and absorber temperatures are the same in all cases, that is, $\mathrm{T}_{\mathrm{a}}=\mathrm{T}_{\mathrm{c}}$.

Table 1 shows the thermodynamic data for the single effect absorption refrigeration system, operating under the following conditions: $\mathrm{T}_{\mathrm{g}}=110^{\circ} \mathrm{C} ; \mathrm{T}_{\mathrm{e}}=5^{\circ} \mathrm{C} ; \mathrm{T}_{\mathrm{c}}=\mathrm{T}_{\mathrm{a}}=$ $40^{\circ} \mathrm{C} ; \mathrm{T}_{0}=25^{\circ} \mathrm{C} ; \varepsilon_{\text {pump }}=1 ; \eta_{\mathrm{ICS}}=\eta_{\mathrm{ICR}}=\eta_{\mathrm{ICSR}}$ $=0.8$; and $52.8 \mathrm{~kW}$ of cooling charge. To solve the equations raised in the previous section, a code was developed in the MATLAB programming environment that uses the database of thermodynamic properties contained in Coolprop. The reference state used for the refrigerant properties was IIR.

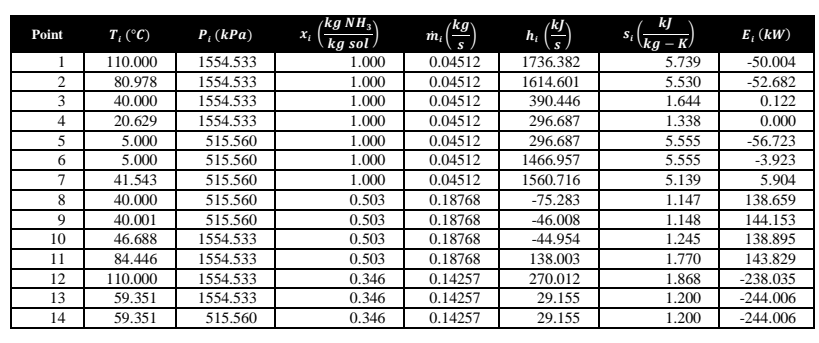

Table 1 SRA thermodynamic data using working torque $\mathrm{NH}_{3}-\mathrm{H}_{2} \mathrm{O}$

Table 2 shows a comparison between the energy and work loads of the SRA components operating under the same working conditions, but at different levels of efficiency in the exchangers, which operate simultaneously. The sum of heat added to the cycle in the generator and the evaporator, is equal to the sum of heat rejected in the condenser and absorber plus the work done towards the system by the pump.

\begin{tabular}{|l|r|r|r|}
\hline \multicolumn{1}{|r|}{$\eta_{I C}=0.6$} & \multicolumn{1}{c|}{$\eta_{I C}=0.8$} & $\eta_{I C}=1$ \\
\hline$Q_{g}(k W)$ & 101.99 & 90.935 & 80.827 \\
\hline$Q_{c}(k W)$ & 57.762 & 55.231 & 52.800 \\
\hline$Q_{e}(k W)$ & 52.800 & 52.800 & 52.800 \\
\hline$Q_{a}(k W)$ & 97.230 & 88.702 & 81.021 \\
\hline$W_{m e}(k W)$ & 0.2018 & 0.1977 & 0.1939 \\
\hline$C O P$ & 0.5167 & 0.5794 & 0.6517 \\
\hline$E C O P$ & 0.1663 & 0.1864 & 0.2095 \\
\hline
\end{tabular}

Table 2 Results of the first law and second law analysis for an SRA using $\mathrm{NH}_{3}-\mathrm{H}_{2} \mathrm{O}$

For the construction of the graph shown in Figure 2, it was considered that the temperature of the condenser and absorber would remain constant at a value of $40^{\circ} \mathrm{C}$ and multiple temperatures were proposed in the evaporator to compare the thermal load required in the generator. It can be seen how the increase in the generation temperature has a significant impact with a very long slope with the increase in temperature $\mathrm{T}_{\mathrm{g}}$ until it reaches an optimal operating temperature and then decreases for a long time. The different values of $\mathrm{T}_{\mathrm{e}}$ illustrate that the energy need increases as it is required to reach lower refrigeration temperatures.

From Figure 2, we can conclude that a relatively high temperature heat source produces a lower temperature cooling capacity with a relatively high energy efficiency and a relatively low temperature heat source produces a high temperature cooling capacity with a relatively low energy efficiency. 
Thus, for example, if the need for cooling was $-10^{\circ} \mathrm{C}$, the best option would be a thermal source of approximately $115^{\circ} \mathrm{C}$, and if instead of that, a space will need to be conditioned at $5^{\circ}$ $\mathrm{C}$, the best alternative in this case it would be a thermal source of $90^{\circ} \mathrm{C}$. Therefore, it is not economical to use a high temperature heat source to obtain high temperature cooling capacity (Cai, He, Tian, \& Tang)..

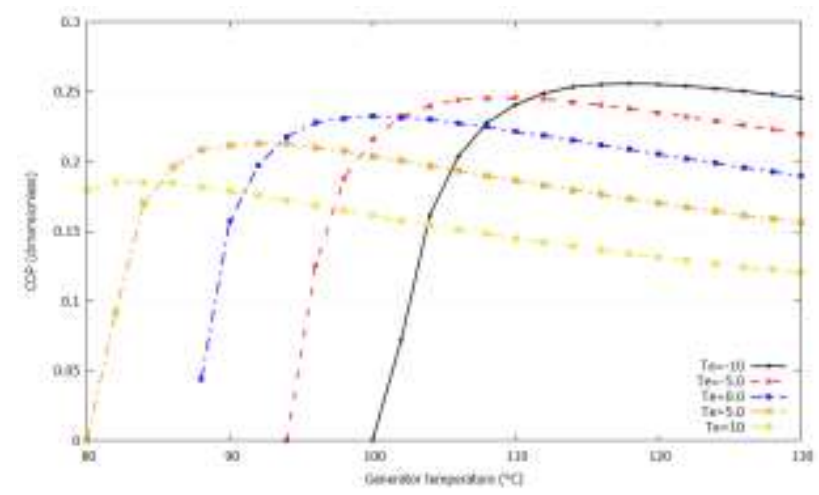

Figure 2 Variation of the coefficient of operation with generator temperature

Figure 3 shows a comparison of the energy efficiency against the generator temperature, in this case at different levels of efficiency in the ICR, ICS and ICSR exchangers, the evaporation temperature considered was $10^{\circ}$ C. The energy efficiency of the system increases dramatically in the initial stage and then slows down. According to the information presented in Figures 2 and 3, the system increases its performance with the increase in the generation temperature, therefore, the determination of an optimal generation temperature will be a key method to improve the performance of the system. As might be expected, the improvement in the efficiency of the exchangers also has positive consequences in the COP.

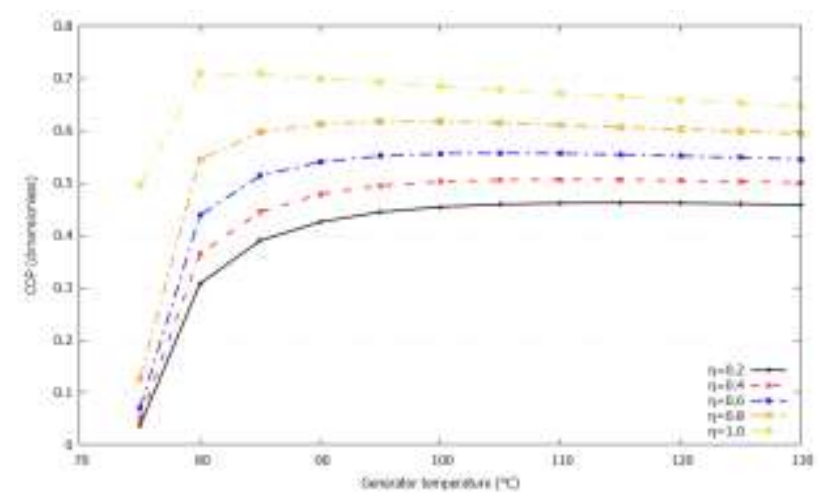

Figure 3 Variation of COP with generation temperature
The effects on the energy operating coefficient that increase the temperature in the absorber, is illustrated in Figure 4, raising the operating temperature of the absorber leads to adverse results in the COP.

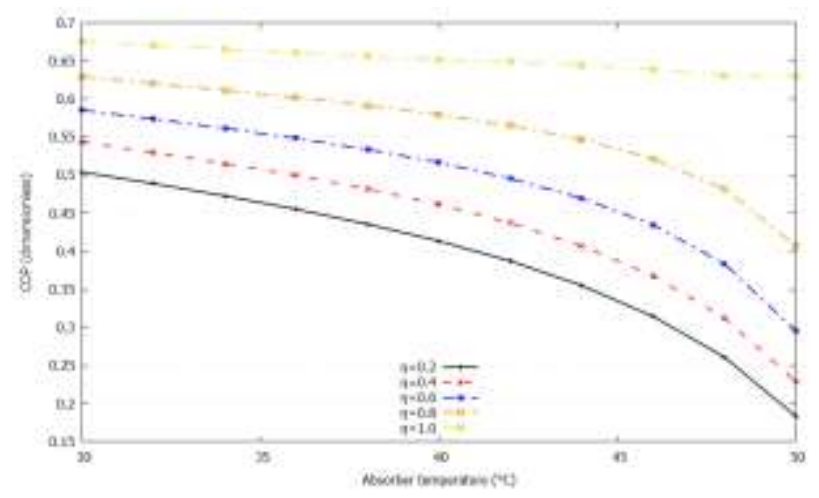

Figure 4 Variation of COP with absorber temperature

The variation of exergy efficiency with generation temperature is shown in Figure 5. Initially, the efficiency increases dramatically and then decreases as $\mathrm{T}_{\mathrm{g}}$ increases. Taking into account that the temperature in the evaporator remains constant in this graph, it follows that there is no single optimal generation temperature for maximum exergetic use, but rather that it varies around the efficiency of the economizers. On the other hand, the graph indicates that the lowest irreversibilities are achieved with the highest efficiency levels of the exchangers.

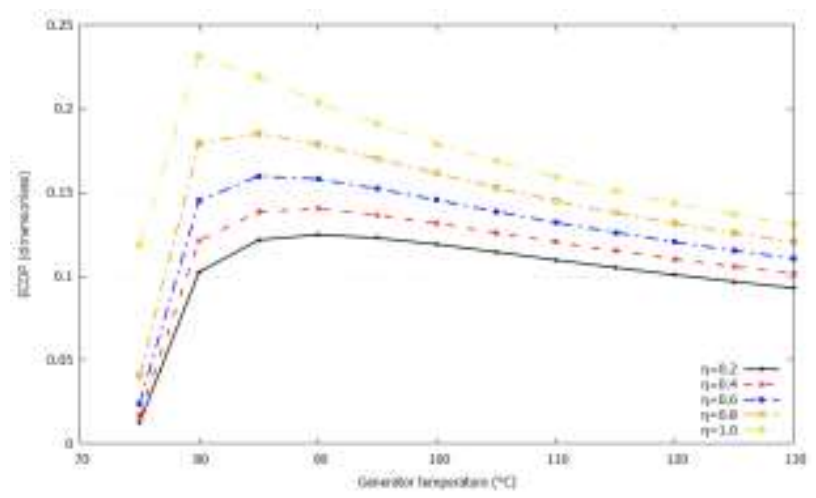

Figure 5 Variation of the exergetic operating coefficient with the generator temperature

The graph shown in Figure 6 was developed at different generation temperatures to analyze the behavior of the ECOP against the evaporator temperature. In view of the fact that, under the same temperature conditions of the generator and condenser, the exergetic efficiency increases with the increase in the evaporator temperature and then decreases, it is concluded that, for each ECOP curve against $T_{e}$ there is a maximum value of exergetic efficiency

VALENCIA-ALEJANDRO, Eric A., HERRERA-ROMERO, José V., COLORADO-GARRIDO, Darío and SILVA-AGUILAR, Oscar F. Exergy analysis of the absorption refrigeration cycle using economizers. Journal of Technological Development. 2020 
That is, when $\mathrm{T}_{\mathrm{g}}, \mathrm{T}_{\mathrm{c}}$ and $\mathrm{T}_{\mathrm{a}}$ are specified, there must be an optimal value of evaporator temperature $T_{e}$, below which the maximum energy of the system is used. In practice, the evaporator temperature is usually a known data that is determined by the requirements of the process, and the generation temperature is usually not difficult to adjust to achieve an optimal operating state of the system..

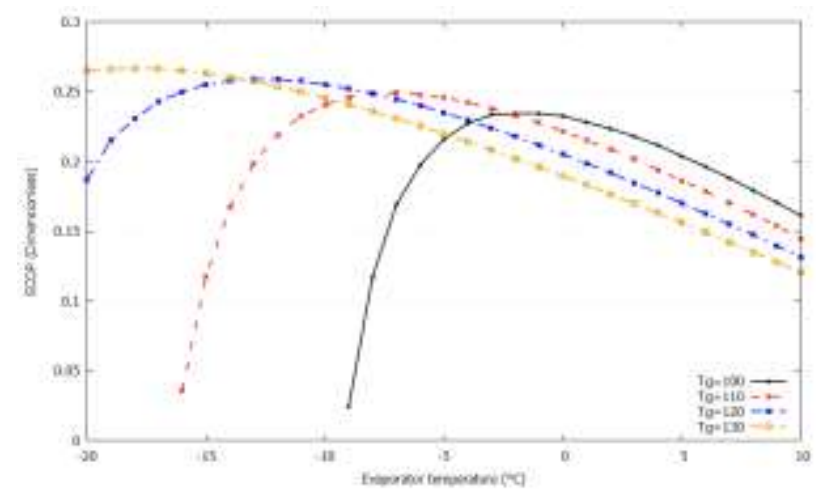

Figure 6 Variation of the exergy operating coefficient with evaporator temperature

As can be seen in Figure 7, the exergy destroyed in both the evaporator and the condenser tiny in relation to the exergy produced in the generator or that destroyed in the absorber. The exergy trend in the generator indicates that the energy needed to complete the refrigeration cycle decreases as the efficiency in the exchangers improves, likewise, the exergy destroyed in the absorber decreases.

What has been said so far supposes that the energy reused at the generator output, both in the ICSR and in the ICS, increases the temperature of the mixture at its inlet, reducing the thermal load required for the boiling of the refrigerant. Likewise, the energy transferred in the ICR and ICS, reduce the amount of heat to disperse in the absorber.

The latter represents an advantage, because it increases the absorption capacity, since by itself, the mixture between refringent and absorbent represents an exothermic process that reduces its dissolution capacity as its temperature increases. As both the diluted solution and the refrigerant enter the absorber at lower temperatures than they would have without the existence of the exchangers, the resulting mixture has a higher concentration of ammonia.

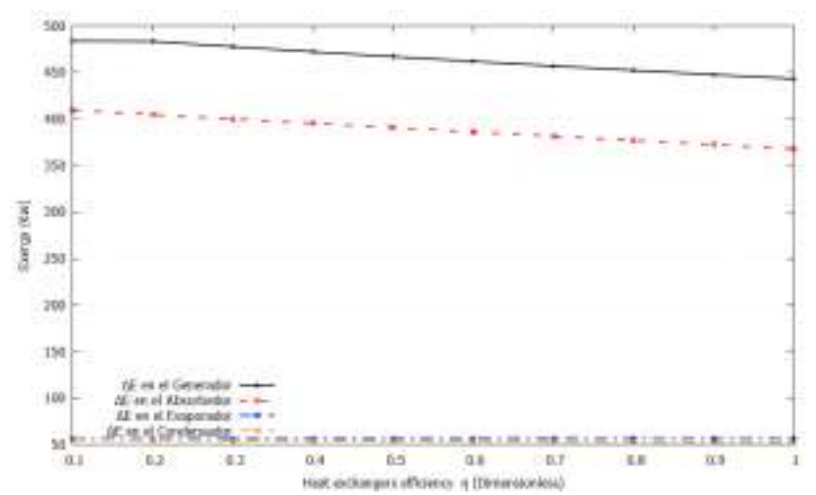

Figure 7 Exergy in the generator, absorber, evaporator and condenser, against the heat exchangers efficiency

\section{Conclusion}

In this work, the first and second laws of thermodynamics were applied to a SRA with economizers. The operation of the cycle and the effects of the addition of exchangers were described, as well as the equations that model the cycle from an energetic and exergetic aspect. In addition, a numerical example was made in which the thermodynamic properties of each state indicated in Figure 1 were defined.

It is concluded then that the decrease in the thermal load on the generator increases the COP. As demonstrated in this research, better thermodynamic performances can be achieved by supplying low-grade residual heat than by operating with excess temperatures in the generator. From the exergy study, it can be inferred that the best way to increase cycle efficiency is by optimizing the economizers. It is clear that, by increasing the energy transfer rate that is recovered at the generator output, the energy destroyed in both the absorber and the condenser is reduced, causing an improvement in the ECOP. In addition to this, the recirculation of heat towards the generator reduces the energy load required for generation, making the cycle more economically attractive.

The main priority to improve the efficiency of the cycle should be to improve the efficiency of the exchangers and secondly, to modify the evaporator temperature. However, as the $T_{e}$ value is usually a set value, subject to the needs of a process, it is recommended to delegate that responsibility to the generator. 


\section{Nomenclature}

$\begin{array}{ll}\dot{m} & \text { Mass flow }[\mathrm{kg} / \mathrm{s}] \\ x & \text { Concentration }[\mathrm{Kg} \text { of refrigerant / } \mathrm{kg} \text { of } \\ & \text { solution] } \\ P & \text { Pressure }[\mathrm{Pa}] \\ T & \text { Temperature }\left[{ }^{\circ} \mathrm{C}\right] \\ h & \text { Enthalpy }[\mathrm{J} / \mathrm{kg}] \\ s & \text { Entropy }[\mathrm{J} / \mathrm{Kg}-\mathrm{K}] \\ v & \text { Specific volume }\left[\mathrm{m}^{\wedge} 3 / \mathrm{kg}\right] \\ \dot{E} & \text { Exergy flow }[\mathrm{kW}] \\ \dot{Q} & \text { Heat flow }[\mathrm{kW}] \\ \dot{W} & \text { Work }[\mathrm{kW}] \\ \eta & \text { Efficiency } \\ \varepsilon & \text { Effectiveness } \\ \text { Subscripts } \\ g & \text { Generator } \\ a & \text { Absorber } \\ e & \text { Evaporator } \\ c & \text { Condenser } \\ I C S & \text { Solution heat exchanger } \\ I C R & \text { Refrigerant heat exchanger } \\ I C S R & \text { Solution-refrigerant heat exchanger } \\ i S O & \text { Isoentropic } \\ m e & \text { Mechanical } \\ i & \text { Status points } \\ 0 & \text { Dead state }\end{array}$

\section{References}

Kaynakli, O., \& Kilic, M. (2007). Theoretical study on the effect of operating conditions on performance of absorption refrigeration system. Energy Conversion and Management, 48(2), 599-607.

Aphornratana, S., \& Eames, I. W. (1995). Thermodynamic analysis of absorption refrigeration cycles using the second law of thermodynamics method. International journal of refrigeration, 18(4), 244-252.

Faires, V. M., \& Simmang, C. M. (1983). Termodinámica. 6. México: Uteha.

Herrera-Romero, J. V., \& Colorado-Garrido, D. (2020). Comparative Study of a CompressionAbsorption Cascade System Operating with NH3-LiNO3, NH3-NaSCN, NH3-H2O, and R134a as Working Fluids. Processes, 8(7), 816:831.

Kilic, M., \& Kaynakli, O. (2007). Second lawbased thermodynamic analysis of water-lithium bromide absorption refrigeration system. Energy, 32(8), 1505-1512.
Karamangil, M. I., Coskun, S., Kaynakli, O., \& Yamankaradeniz, N. (2010). A simulation study of performance evaluation of single-stage absorption refrigeration system using conventional working fluids and alternatives. Renewable and Sustainable Energy Reviews, 14(7), 1969-1978.

Sun, D. W. (1998). Comparison of the performances of NH3-H2O, NH3-LiNO3 and NH3-NaSCN absorption refrigeration systems. Energy Conversion and Management, 39(5-6), 357-368.

Soleymani, A. G. (2007). Simple equations for predicting entropy of ammonia-water mixture.

Sözen, A. (2001). Effect of heat exchangers on performance of absorption refrigeration systems. Energy Conversion and Management, 42(14), 1699-1716.

Panahi, Z. F., \& Bozorgan, N. (2011). The energy and exergy analysis of single effect absorption chiller.INT J Advanced Desing and manufacture Technology, 4(4), 19-26.

Gonzáles C., Israel (2014). Análisis exergético del sistema de refrigeración por absorción regenerativo $\mathrm{NH} 3-\mathrm{H} 2 \mathrm{O}$ (Tesis de pregrado). Universidad Nacional Autónoma de México, Distrito Federal, México.

Cai, D., He, G., Tian, Q., \& Tang, W. (2014). Exergy analysis of a novel air-cooled nonadiabatic absorption refrigeration cycle with NH3-NaSCN and NH3-LiNO3 refrigerant solutions. Energy conversion and management, 88, 66-78. 